\title{
Rapid Biosynthesis of Silver Nanoparticles by Exploiting the Reducing Potential of Trapa bispinosa Peel Extract
}

\author{
Sunil Pandey, Ashmi Mewada, Mukeshchand Thakur, Sachin Shinde, \\ Ritu Shah, Goldie Oza, and Madhuri Sharon \\ N.S.N. Research Institute for Nanotechnology and Bionanotechnology, Ambernath, Maharashtra 421501, India \\ Correspondence should be addressed to Sunil Pandey; gurus.spandey@gmail.com \\ and Madhuri Sharon; sharonmadhuri@gmail.com
}

Received 16 April 2013; Accepted 23 July 2013

Academic Editor: Irshad Hussain

Copyright (C) 2013 Sunil Pandey et al. This is an open access article distributed under the Creative Commons Attribution License, which permits unrestricted use, distribution, and reproduction in any medium, provided the original work is properly cited.

Present work reports exceptionally high reducing capacity of Trapa bispinosa to synthesize monodispersed silver nanoparticles (SNPs) within 120 seconds at $30^{\circ} \mathrm{C}$ which is the shortest tenure reported for SNP synthesis using plants. Moreover, we also instigated impact of different $\mathrm{pH}$ values on fabrication of SNPs using visible spectroscopy with respect to time. Percentage conversion of $\mathrm{Ag}^{+}$ ions into $\mathrm{Ag}^{\circ}$ was calculated using ICP-AES analysis and was found to be $97 \%$ at $\mathrm{pH}=7$. To investigate the reduction of $\mathrm{Ag}^{+}$ions to SNPs, cyclic voltammetry $(\mathrm{CV})$ and open circuit potential $(\mathrm{OCP})$ using $0.1 \mathrm{M} \mathrm{KNO}_{3}$ were performed. There was prompt reduction in cathodic and anodic currents after addition of the peel extract which indicates the reducing power of T. bispinosa peel. Stability of the SNPs was studied using flocculation parameter (FP) which was found to be least at all the pH values. FP was found to be indirectly proportional to stability of the nanoparticles.

\section{Introduction}

Marriage of biology with nanotechnology was one of the most fruitful outcomes in material research, particularly in synthesis of metallic nanoparticles such as gold and silver. Living systems have learned over the tenure of millions of years of evolution to combat metal toxicity. In order to deplete the toxic effects of the metal ions, organisms release enzymes and other reducing agents to lower the oxidation states [1]. Recently, the molecular capacity of plants [2], bacteria [2, $3]$, and algae [4] to convert metal ions into well-dispersed nanoparticles has been explored. Tuning the parameters for the synthesis of nanoparticles of desired optical properties offers an intelligent and economical solution to avoid the toxicity as well as cost factor for biological applications like targeted drug delivery unlike chemical methods such as molecular beam epitaxy [5] and chemical vapour deposition [6] which involves toxic materials as precursors and expensive sophisticated techniques.

The most challenging endeavours in exploiting these living systems for commercial production of nanoparticles are as follows.
(1) Living organisms require very stringent parameters to produce nanoparticles of desired size and shape.

(2) Due to complex physiological circuits found in living systems, it becomes a daunting task to predict the modus operandi for nanoparticle synthesis so that a chemical reaction can be established.

(3) Time required for the synthesis can vary from few minutes to few days.

(4) Purification of the nanoparticles sometimes becomes difficult, particularly in case of intracellular production of nanoparticles $[7,8]$.

On the other hand advantages offered by living systems are manifold.

(1) Exceptional biocompatibility of the nanoparticles offers widespread avenues for biological application of metal nanoparticles.

(2) Water soluble metal nanoparticles can be obtained which can be used for biological proposes without stringent surface modifications. 
(3) Materials and energy consumption by living systems for the production of nanoparticles are extremely less making it a green alternative.

(4) The process is thermodynamically efficient due to involvement of enzymes and short peptides [9].

(5) Easy availability and low cost are involved in processing of the precursors.

Amongst most of the organisms which are used for the production of nanoparticles, plants are the most celebrated systems due to their inherent capacity to accumulate metals [10]. This capacity can acclimatize plants to withstand higher concentrations of metal ions and hence more production of nanoparticles unlike bacteria and algae which are very sensitive to metal ion concentrations. To name some plants which have been exploited for the production of silver as well as gold nanoparticles there are Alfalfa [11], Neem (Azadirachta indica) [12], Geranium [13], Rose [14], Nelumbo nucifera [15], and Cinnamomum camphora [16]. With a novel aim to use plants as ideal catalysts for commercial production of SNPs having desired properties, we have explored the peel of T. bispinosa (commonly known as Singhara in India) for ultrafast reduction of silver ions $\left(\mathrm{Ag}^{+}\right)$. Few reports on plantmediated green synthesis claim rapid synthesis time [17-19]. However, the time required for SNPs synthesis in current report using $T$. bispinosa peel extract was found to be within $120 \mathrm{sec}$ at room temperature $\left(28 \pm 2^{\circ} \mathrm{C}\right)$ which is one of the very rare reports for SNP synthesis. This is one of the major factors which might be useful commercially for scaling-up SNP production since the formation was very rapid with no surplus addition of heat energy. Impact of different $\mathrm{pH}$ values of the peel extract on the optical as well as morphological properties of SNPs is investigated in detail. Moreover, stability of the respective nanoparticles is studied using a physical quantity called "flocculation parameter" originally given by Weisbecker et al. [20].

\section{Materials and Methods}

2.1. Preparation of the Peel Extracts and Biosynthesis of Silver Nanoparticles. T. bispinosa was procured from the local market and soaked in cold water for $30 \mathrm{~min}$. $10 \mathrm{~g}$ of the peel was crushed in $50 \mathrm{~mL}$ of distilled water and centrifuged to obtain clear light pink coloured extract. The extract was ultrafiltered using $0.22 \mu$ nylon filter (Sartorius, Germany) in millipore apparatus under vacuum. And thus obtained ultraclear extract was used to perform all the experiments. It can be stored for more than a month at $4^{\circ} \mathrm{C}$. Peel extract was diluted $(1: 100)$ using distilled water $(18 \mathrm{M} \Omega) .10 \mathrm{~mL}$ of the diluted extract was adjusted to $\mathrm{pH} 2.8,4.5,5.5,7$, and 10 using $1 \mathrm{~N} \mathrm{NaOH}$ and $1 \mathrm{~N}$ acetic acid to avoid chloride induced flocculation of the SNPs. Under stirring condition at $28 \pm$ $2^{\circ} \mathrm{C}, 10 \mu \mathrm{L}$ from a stock of 50,000 ppm silver nitrate $\left(\mathrm{AgNO}_{3}\right)$ was added in $990 \mu \mathrm{L}$ of diluted T. bispinosa plant extract. The procedure was repeated for all the $\mathrm{pH}$ values. Optimised $\mathrm{pH}$ value ( $\mathrm{pH}$ 10) was used to study the time dependent synthesis of SNPs using UV-Vis spectroscopy.

2.2. Characterization. As formed SNPs were studied using UV-Vis spectrophotometer (Lambda-25 Perkin Elmer, USA),
SNPs synthesized at different $\mathrm{pH}$ values were analysed using Field Emission Gun-Scanning Electron Microscope (Carl Zeiss, Germany) operating at $10 \mathrm{KV}$. Particle size distribution (PSD) was performed using Nano Sight LM20 (Amesbury, $\mathrm{UK})$. Concentration of $\mathrm{Ag}^{+}$ions before and after addition of plant extract was analysed using Inductively Coupled Plasma Atomic Emission Spectroscopy (ICP-AES) using ARCOS, Germany. Equation (1) is used to calculate percentage yield $(\% Y)$ using initial concentration (IC) and final concentration (FC) of $\mathrm{Ag}^{+}$ions:

$$
\% Y=\frac{\mathrm{IC}-\mathrm{FC}}{\mathrm{IC}} \times 100 \%
$$

Surface charge of SNPs with respect to $\mathrm{pH}$ was determined using Zetasizer (Malvern, UK). Cyclic voltammetry (CV) studies to comprehend the reduction of SNPs in the solution triggered by the T. bispinosa peel extract were performed by using Reference 3000 Potentiostat (Gamry, USA) by scanning in the potential range from 0.1 to $0.7 \mathrm{~V}$ at a scan rate of $1000 \mathrm{mV} \mathrm{S}^{-1}$. Electrochemical studies were performed using platinum wire as working electrode and counterelectrode against $\mathrm{Ag} / \mathrm{AgCl}$ as reference electrode. All the measurements were performed at $\mathrm{pH} 7 \pm 2$ at $28 \pm 2^{\circ} \mathrm{C}$. Under stirring condition, in $25 \mathrm{~mL}$ of $0.1 \mathrm{M} \mathrm{KNO}_{3}$ solution, $25 \mu \mathrm{L}$ of 50,000 ppm $\mathrm{AgNO}_{3}$ solution was added. After few initial scans to standardize peaks for silver ions, $0.5 \mathrm{~mL}$ of the $T$. bispinosa peel extract was added. Extremely fast depletion of the peaks for silver ions was observed immediately after addition of the extract. Thermogravimetric analysis (TGA) was done using Seiko Instruments, Japan, at heating rate of $10^{\circ} \mathrm{C} \mathrm{min}^{-1}$.

2.3. Stability and Flocculation Parameter. SNPs synthesized at the above-mentioned $\mathrm{pH}$ values were centrifuged to remove excess reducing agents before performing stability test. Three $\mathrm{mL}$ of the SNPs synthesised at respective $\mathrm{pH}$ was taken in a quartz cuvette, and initial spectrum was recorded between 400 and $800 \mathrm{~nm} .100 \mu \mathrm{L}$ of $5 \mathrm{M} \mathrm{NaCl}$ salt was added to the same cuvette, and spectrum was recorded to see effect of salt in the form of red or blue shift of the maximum absorbance peak in the spectrum. This procedure was repeated till the peak became flat or stable.

Flocculation parameters were calculated by measuring the integrated absorbance between 450 and $750 \mathrm{~nm}$ in case of SNPs [21]. Equation (2) was used to calculate the integrated absorbance:

$$
P=\int_{450}^{750} I_{\mathrm{Abs}} \lambda(d x) .
$$

\section{Results and Discussion}

3.1. Synthesis of SNPs. One of the key requirements for efficient production of the metal nanoparticles is their rapidity of formation as well as monodispersity after addition of the reducing agents. In our work, reduction of the silver ions into SNPs was catalysed within $120 \mathrm{sec}$ at $28 \pm 2^{\circ} \mathrm{C}$ after addition of the peel extract. This is a very short time for synthesis 
of SNPs using plant extract unlike earlier observations using biological systems which report formation of the SNPs after $24 \mathrm{~h}$ at $30^{\circ} \mathrm{C}$ [22-24].

Figure 1(a) explains the time dependent ripening of SNPs formation at $\mathrm{pH} 7$ (inherent $\mathrm{pH}$ of the peel extract). A slight hump at $427 \mathrm{~nm}$ can be seen in the initial spectrum $(0 \mathrm{~min})$ which was recorded immediately after addition of the silver salt. There was considerable enhancement of peak intensity after $5 \mathrm{~min}$ followed by a slight red shift $(11 \mathrm{~nm})$ and decrease in full width half maxima (FWHM) as $30.03 \mathrm{~nm}$ as shown in the of Figure 1(b). FWHM determines the size and shape dispersity of nanoparticles; for calculations see Supplementary Information Scheme 1 available online at http://dx.doi.org/10.1155/2013/516357. Inset of Figure 1(a) shows increase in the absorbance of the SNPs with increase in time which in turn shows the rapid formation of SNPs in the solution. There were more red shifts and increase in FWHM after $10 \mathrm{~min}$ of the reaction between silver salt and peel extract. Red shift indicates the ripening of the nanoparticles [25] whereas increase in FWHM explains the increase in the polydispersity of SNPs as per Mie theory [26]. There was consistent growth in the peak intensity accompanied with the red shift from $427 \mathrm{~nm}$ to $446 \mathrm{~nm}$ indicating the increase in the concentration of nanoparticles.

Any agglomeration of the nanoparticles in the solution can be ruled out due to sharpness of the peaks. This was also speculated due to the absence of turbidity in the SNP solution. A detailed study of agglomeration is presented in later part of the discussion. Abruptness in FWHMs with respect to time may be caused due to size and shape distributions of the nanoparticles during the rapid reduction process of silver ions to SNPs.

Exceptionally high reducing property of $T$. bispinosa extract may be attributed due to its inherent antioxidant property [27]. Presence of high quantity of flavonoids [28], polyphenols [29], and starch [30] can be the cause for such high reducing capacity at ambient temperature.

3.2. Characterization of SNPs. Time dependent appearance of colour at respective $\mathrm{pH}$ values $(2.8,4.5,5.5,7$, and 10) is shown in Figure 2(a). Appearance of the peaks at different $\mathrm{pH}$ values between 400 and $500 \mathrm{~nm}$ wavelength is due to size related phenomenon called surface plasmon resonance [31] as displayed in Figure 2(b) along with the colours of SNPs after complete reduction of $\mathrm{Ag}^{+}$(inset of Figure 2(b)).

At $\mathrm{pH} 2.8$, slightly pink colour appeared after addition of the peel extract which became slightly blue after $120 \mathrm{sec}$ (Figure 2(a)). Feeble spectral property (Figure 2(b)) shows formation of roughly spherical nanoparticles of size range ca. 9-70 $\mathrm{nm}$ (Figure 3(A)) due to unfavourable redox states of reducing agents present in the peel extract as well as $\mathrm{Ag}^{+}$ ions. It may also be due to unstable proteins or short peptides at lower $\mathrm{pH}$ which play cardinal role in formation as well stability of the nanoparticles.

At $\mathrm{pH} 4.5$ rapid formations can be seen, in stark contrast to acidic $\mathrm{pH}$ 2.8. As presented in Figure 2(a), colour of the solution appeared within 15 seconds after addition of the extract which became darker with increase in time, and finally greenish colour was exhibited after $120 \mathrm{sec}$ (inset of
Figure 2(b)). Synthesis of SNPs was confirmed by increase in the intensity of the peak at $426 \mathrm{~nm}$ (Figure 2(b)).

SEM results show SNPs of roughly spherical morphology (Figure 3(B)). These results are consistent with PSD results (Figure 3(B), right panel) which display particle size 20$100 \mathrm{~nm}$. Moreover, some larger nanoparticles (>120 nm) can also be seen. This variation of results (in comparison to SEM) may be due to different fields selected for the examination. Very little amount of nonspherical nanoparticles can be seen making the process efficient for the production of spherical nanoparticles.

At $\mathrm{pH}$ 5.5, comparatively faster reduction of $\mathrm{Ag}^{+}$ions and hence appearance of colour can be seen in Figure 2(a). There was slight red shift of $3 \mathrm{~nm}$ at $\mathrm{pH} 5.5$ as compared to 4.5. A comparatively sharper peak at $419 \mathrm{~nm}$ indicates the monodispersity of the nanoparticles (Figure 2(b)). Also, increase in the intensity shows enhanced ripening of SNPs. SEM image displays highly monodispersed spherical nanoparticles on an average ranging from 10 to $80 \mathrm{~nm}$ (Figure 3(C)). No evidence of flocculation can be seen in the image. With increase in the $\mathrm{pH}$ value better size control can be seen as evident from the SEM images. This may be due to the presence of capping proteins in their thermodynamically efficient state when the $\mathrm{pH}$ approaches alkalinity. Role of these capping proteins is to navigate the growth of the crystal in the solution based on their surface energies. These short peptides or other surfactants present in plant extract mimic nanotemplates to assist nucleation to initiate ripening as well as shape of the nanoparticles depending on the surface energies. Additionally, capping proteins provide surface charge to nanoparticles in order to resist their agglomeration in the solution $[32,33]$.

At $\mathrm{pH}$ 7, a peak became less intense and broader at $413 \mathrm{~nm}$. In this case, a blue shift of $6 \mathrm{~nm}$ was observed (from 419 to $413 \mathrm{~nm}$ ). Blue shift is an indicative of decrease in the diameter of the nanoparticles as well as its stabilization in the solution. The observation can also be verified from the SEM image (Figure 3(D)). Nanoparticles were in the range of 6-100 nm. Diameter of the particles got decreased to less than $20 \mathrm{~nm}$ along with some larger nanoparticles. This may be due to the repulsion between the nanoparticles by virtue of negative charge of the surfaces. Also, at inherent $\mathrm{pH}$ of the peel extract capping proteins must be in their most efficient state in terms of thermodynamics; hence a better size tuning can be seen.

Extremely alkaline $\mathrm{pH}(\mathrm{pH} 10)$ had profound influence on the formation of SNPs. Exceptionally fast reduction of the nanoparticles can be seen in Figure 2(a). After complete reduction, sharp peak at $408 \mathrm{~nm}$ and wine red colour of the SNPs (Figure 2(b) and its inset, resp.) can be seen. Blue shift of $5 \mathrm{~nm}$ indicates the further decrease in the particle diameter below $10 \mathrm{~nm}$. As per the PSD analysis (Figure 3(E), right panel), particles were found to range from ca. 5 to $80 \mathrm{~nm}$. Evidence of more stabilization can be seen in electron micrograph (Figure 3(E)). The energy dispersive $\mathrm{X}$-ray (EDAX) spectroscopy presented in Figure S2 shows presence of pure silver. The percentage weight by weight of Ag as obtained from EDAX spectra was found to be ca. $8.24 \%$.

Reduction of silver ions to form SNPs in solution was also verified by $\mathrm{CV}$ by assessing the change in the oxidation 


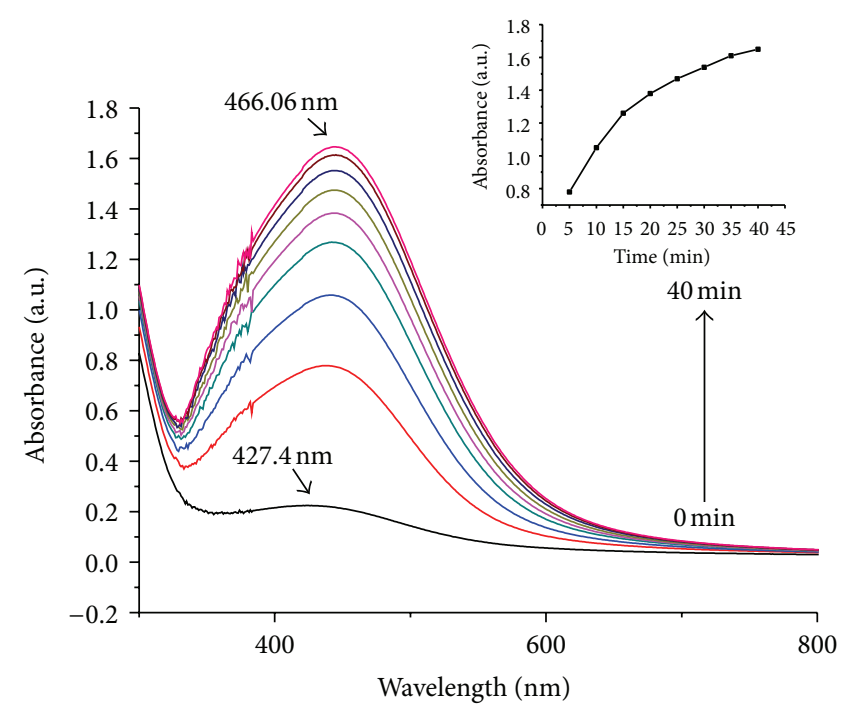

(a)

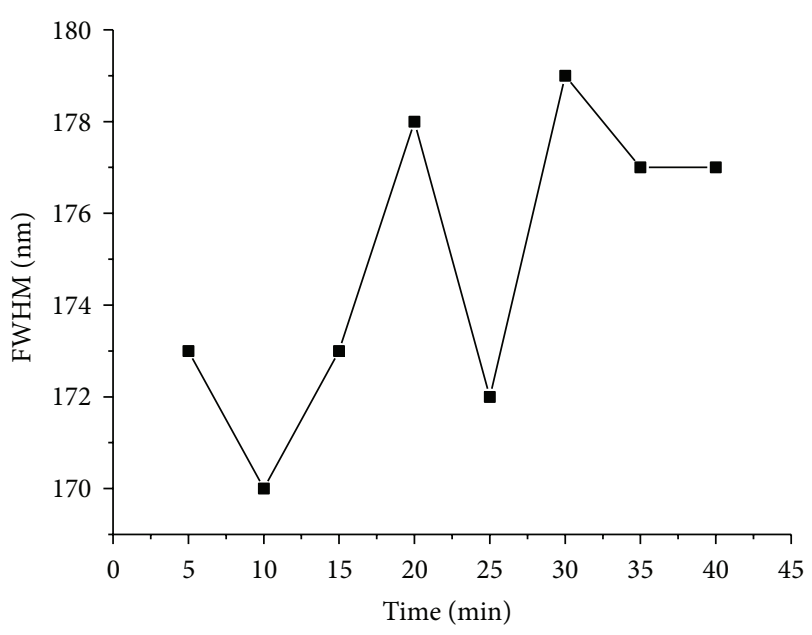

(b)

FIgURE 1: (a) UV-Vis spectra displaying the ultrafast biofabrication of SNPs using T. bispinosa peel extracts with respect to time (0-40 min). Inset shows increase in absorbance of the SNPs with respect to time and (b) FWHM of the peaks with respect to time.

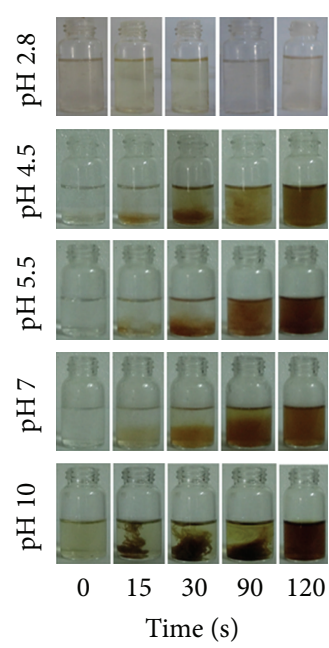

(a)

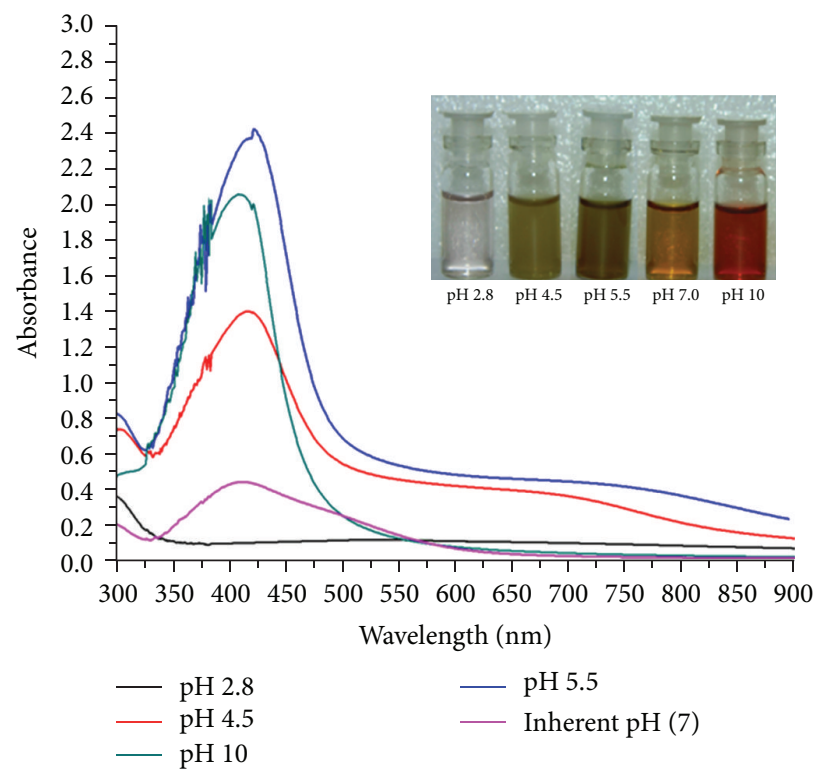

(b)

FIGURE 2: (a) Pictorial snapshots showing formation of SNPs at different pH values (in seconds). (b) UV-visible spectroscopy of SNPs synthesised using T. bispinosa peel extract at different $\mathrm{pH}$ values. Inset shows colours of SNPs due to SPR.

states of silver ions (Figure 4(a)). CV is a simple technique to record the redox potential of the species which are under experimental consideration. To comprehend the reduction potential of $T$. bispinosa peel extract, voltage range was selected to be $0.1-1 \mathrm{~V}$ [34].

Peaks observed at 0.46 and $0.28 \mathrm{~V}$ are assigned to reduction and oxidation potentials of $\mathrm{AgNO}_{3}$, respectively. In $25 \mathrm{~mL} 0.1 \mathrm{M} \mathrm{KNO}_{3}$ containing $25 \mu \mathrm{L}$ of $50,000 \mathrm{ppm} \mathrm{AgNO}_{3}$ a prominent peak at 0.46 was observed at a scan rate of $1000 \mathrm{mV} \mathrm{S}^{-1}$. Immediately after the addition of $0.5 \mathrm{~mL}$
T. bispinosa peel extract, there was drastic shift in the potential towards negativity followed by reduction in the current density. This was clear indication of formation of SNPs in the solution which was also accompanied by change in colour from pale yellow to yellowish brown. Another pivotal observation was prompt decrease in the cathodic current density within few seconds after the addition of the extract implying the rapid reduction efficiency of peel extract.

Open circuit potential (OCP) under the above experimental conditions was performed to check time required for 


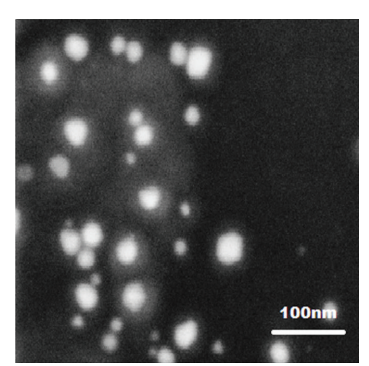

(A)

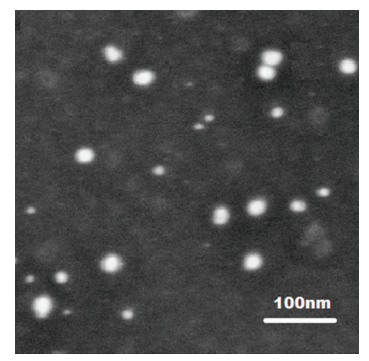

(B)

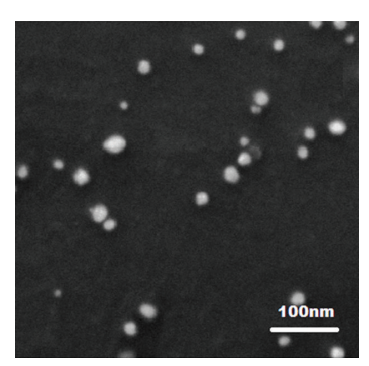

(C)

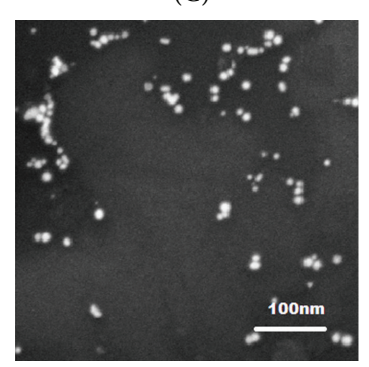

(D)

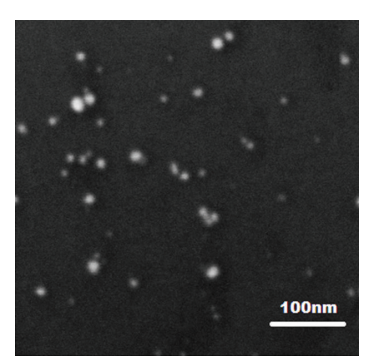

(E)

(a)
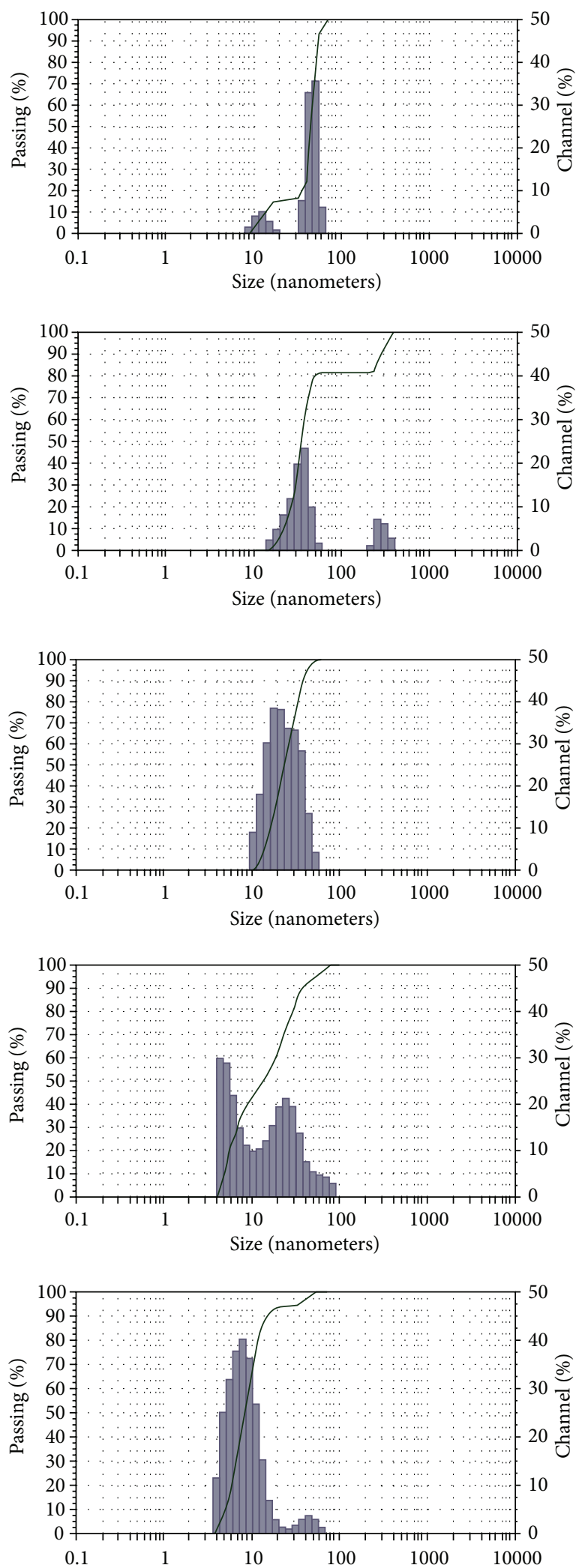

Size (nanometers)

(b)

FIGURE 3: FE-SEM image (a) of SNPs biofabricated at pH (A) 2.8, (B) 4.5, (C) 5.5, (D) 7, and (E) 10 and dynamic light scattering (DLS) (b) of respective SNPs showing particle size distribution. 


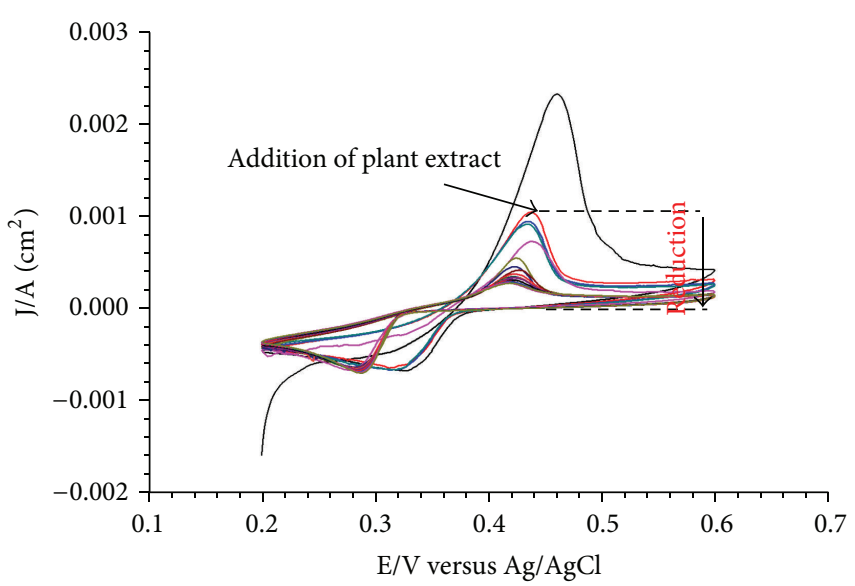

(a)

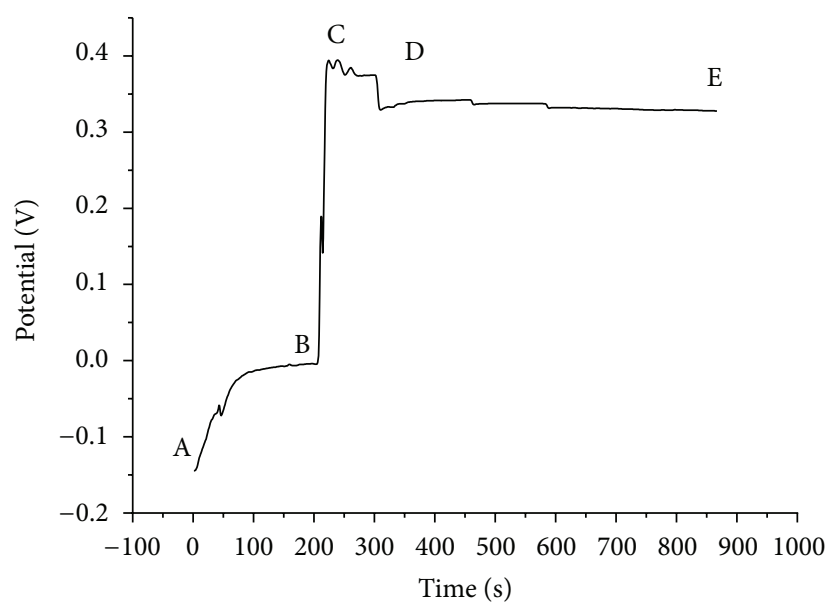

(b)

FIGURE 4: (a) Cyclic voltammetry showing the rapid reduction of silver ions using silver electrode as reference and scan rate of $1000 \mathrm{mV} \mathrm{S}^{-1}$ (arrow is showing the event of addition of plant extract in the reaction mixture) and (b) open circuit potential during the synthesis of SNPs, points $\mathrm{A}-\mathrm{B}$ represent the potential of $\mathrm{KNO}_{3}$ after addition of $\mathrm{AgNO}_{3}$ solution, $\mathrm{C}$ is the point where the plant extract was added, and $\mathrm{D}$-E show wide constant potential of SNPs after reduction of $\mathrm{Ag}^{+}$ions to $\mathrm{Ag}^{0}$.

the reduction of the silver ions against potential. As shown in Figure $4(\mathrm{~b})$, potential of pure $\mathrm{KNO}_{3}(\mathrm{~A}-\mathrm{B})$ increased due to addition of the $\mathrm{AgNO}_{3}$ till $\mathrm{C}$. There was abrupt drop in the potential immediately after the addition of the peel extract which became constant after few seconds. This indicates the ultrafast reduction of $\mathrm{AgNO}_{3}$ to form SNPs mediated by peel extract.

Powder X-ray diffraction shows the crystalline nature of biosynthesised SNPs (Figure S3). Arrangement of atomic arrangement within the crystal and size of SNP were calculated. Comparison with the standard (joint committee in powder diffraction standards file no. 04-0783) confirmed that the particles were SNPs as depicted by the peaks at $2 \theta$ values of $38.40^{\circ}, 44.32^{\circ}$, and $65.11^{\circ}$ corresponding to (111), (200), and (220) planes for SNPs, respectively. This XRD pattern confirms the crystallinity of SNPs. The mean particle size of SNPs was calculated from the XRD data which can be derived from Debye Scherrer Equation

$$
D=\frac{K \lambda / \beta_{1 / 2}}{\cos \theta} .
$$

This equation exploits the reference peak width at angle $(\theta)$, where $\lambda$ is the X-ray wavelength (1.5418), $\beta_{1 / 2}$ is the FWHM of the XRD peak, and $K$ is the shape factor. The calculated average particle size of SNP was ca. $10-15 \mathrm{~nm}$.

ICP-AES analysis of $\mathrm{Ag}^{+}$content after reduction of $\mathrm{AgNO}_{3}$ by plant extract was found to be $1500 \mathrm{ppm}$ at $\mathrm{pH}$ 7. Using (1), the percentage conversion or percent yield (\% Y) was calculated as $97 \%$. Comparative FTIR spectra of peel extract and SNPs synthesized from it show presence of proteins/organic capping of the nanoparticles (Figure S4).

TGA explains the surface protection of SNPs by some unique molecules, most probably short peptides (Figure S5). To remove organic peptide and protein capping of SNPs, peptidases and proteinases, respectively, could be used to degrade them into individual amino acids, and hence the nanoparticles can be used for further functionalization.

3.3. Stability of the SNPs and Flocculation Parameters at Different $p H$ Values. Stability of the SNPs was studied adding multiples of $100 \mu \mathrm{L}$ of $5 \mathrm{M} \mathrm{NaCl}$ with respect to time and recording the spectra after each addition of salt solution. The idea behind this was to study the change in the spectral properties due to flocculation induced by increasing salt concentration. Under the influence of salt, nanoparticles start forming cluster and hence shift in the peak towards longer wavelengths (450-750 $\mathrm{nm}$ in case of SNPs) results [35]. This can be seen in the form of red shift. Physical relation between the origin of the red shift and aggregation of the metal nanoparticles was given originally by Quinten and Kreibig, 1986 [36]. According to their studies, when the distance between flocculating spheres is smaller than the radius of the spheres, the resonance shifts to longer wavelengths.

The more the red shift, the less stable the particle at that salt concentration. Figure 5 shows the spectral properties of SNPs after addition of the salt at $\mathrm{pH} 4.5,5.5,7$, and 10. At $\mathrm{pH}$ 4.5 there was red shift of $11 \mathrm{~nm}$ after addition of approximately $1.5 \mathrm{M} \mathrm{NaCl}$ (Figure 5(a)). Moreover, continuous decrease in the absorbance with respect to time after addition of salt solution can be seen. A mild hump at $677 \mathrm{~nm}$ indicates the agglomeration of nanoparticles in the solution. In contrast to the above observations, there was blue shift of 22,3 , and $8 \mathrm{~nm}$ at $\mathrm{pH} 5.5,7$, and 10, respectively (Figures 5(b)-5(d)). Blue shift in this case can be either due to reduction in the size of SNPs and/or multiple coatings of surface protecting agents on SNPs. It also indicates stabilisation of the SNPs in the solution due to favourable thermodynamic interaction of capping proteins on the surface of SNPs. In agreement with spectral as well as morphological features of SNPs, decrease in the particle size as well as stabilization of the nanoparticles with respect to time can be seen in Figures 3(A)-3(E). 


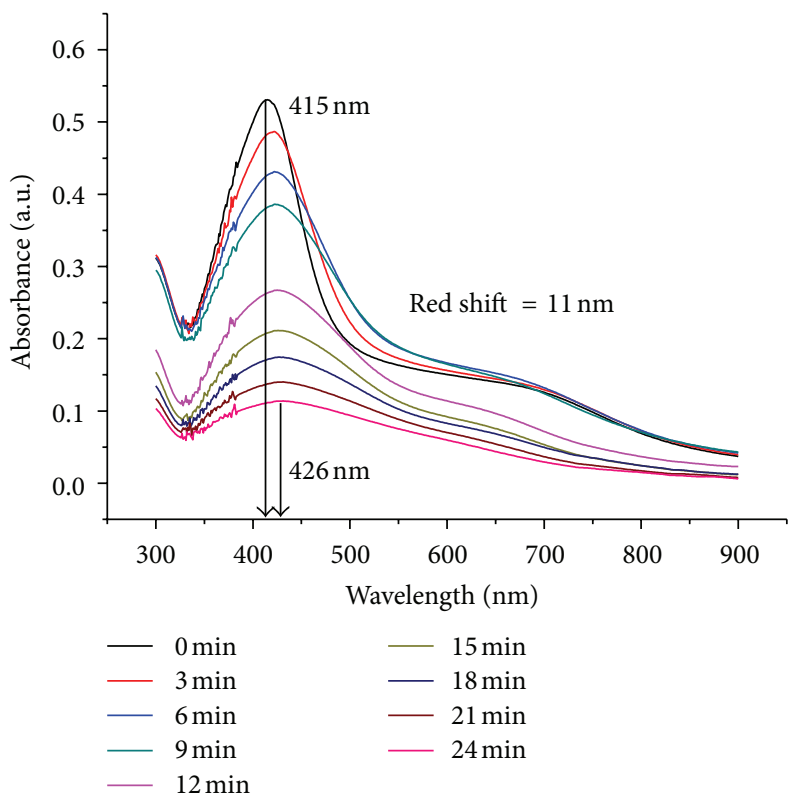

(a)

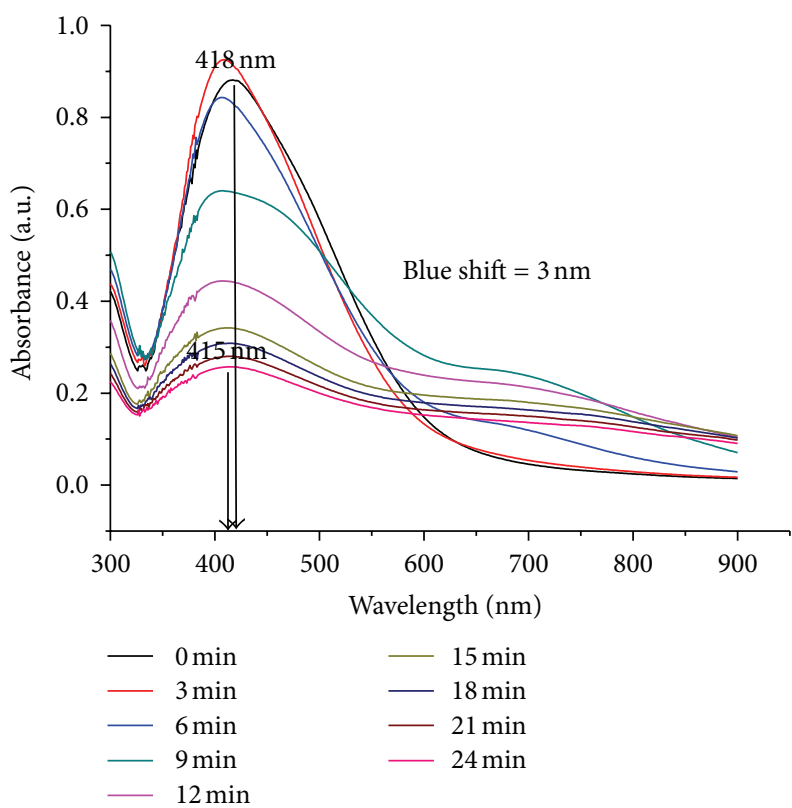

(c)

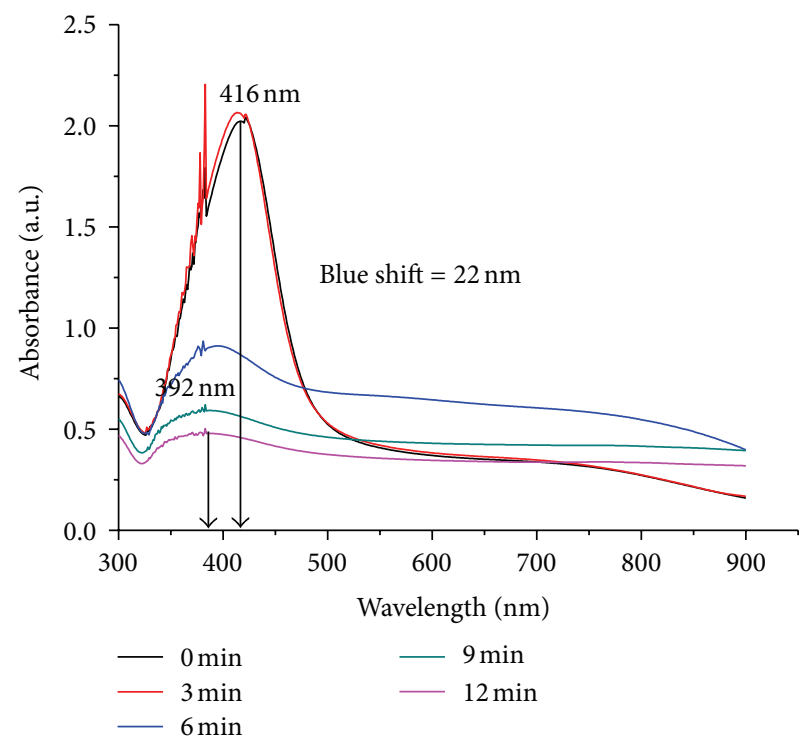

(b)

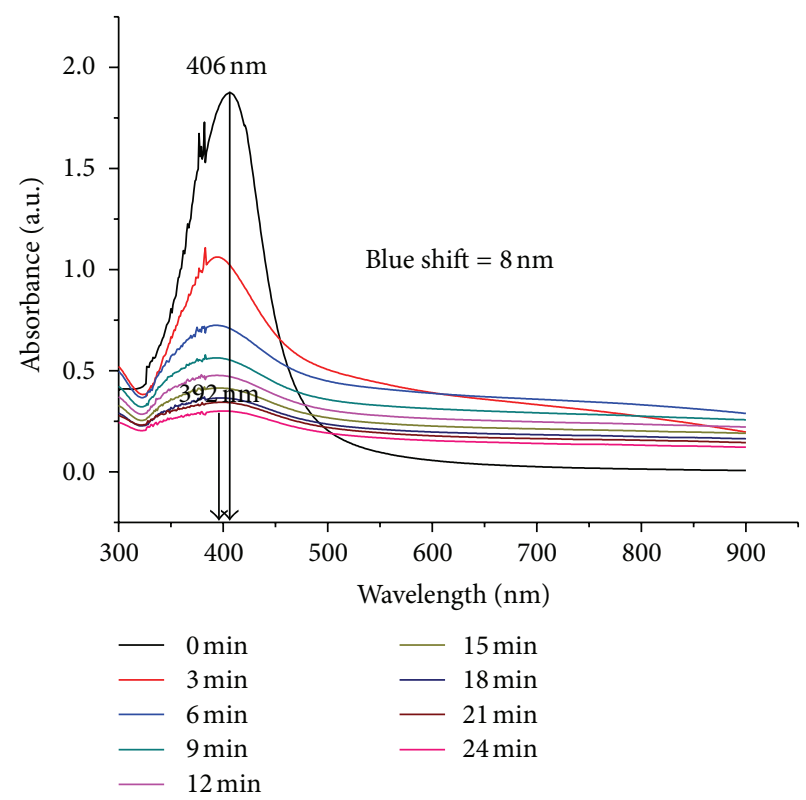

(d)

FIGURE 5: UV-visible spectra showing the change in the optical properties of SNPs with respect to time after addition of the $\mathrm{NaCl}$ at $\mathrm{pH}$ (a) 4.5, (b) 5.5, (c) 7, and (d) 10 .

Another important terminology to display the stability of the nanoparticles is flocculation parameter (FP) originally used by Wiesbecker et al. [20] and partially modified by Sastry et al. [21]. FP of SNPs with respect to time is shown in Figure 6(a). It can be clearly seen that, in $\mathrm{pH}$ value 4.5 , FP was found to be increasing with respect to time indicating the agglomeration or ripening of the SNPs. This finding is also supported by heavy red shift seen at this $\mathrm{pH}$ value (Figure 5(a)). Moreover, presence of slight turbidity in the SNPs (inset of Figure 2(b)) shows agglomeration in agreement with the above finding. The presence of negative charge on SNPs was confirmed by zeta potential studies (Figure 6(b)) which indicates the rapid stabilisation of the nanoparticles in the solution.

At $\mathrm{pH}$ 5.5, FP was found to be increasing with increase in time. This indicates agglomeration of the nanoparticles as evident from the colour of the solution. However, no signs of agglomeration are seen in the SEM image. Blue shift in this case indicated the agglomeration or increase in the multiple coatings on the surface of nanoparticles which may result in agglomeration. At alkaline $\mathrm{pH}$ (7 and 10), FP was found to increase initially but became constant and 


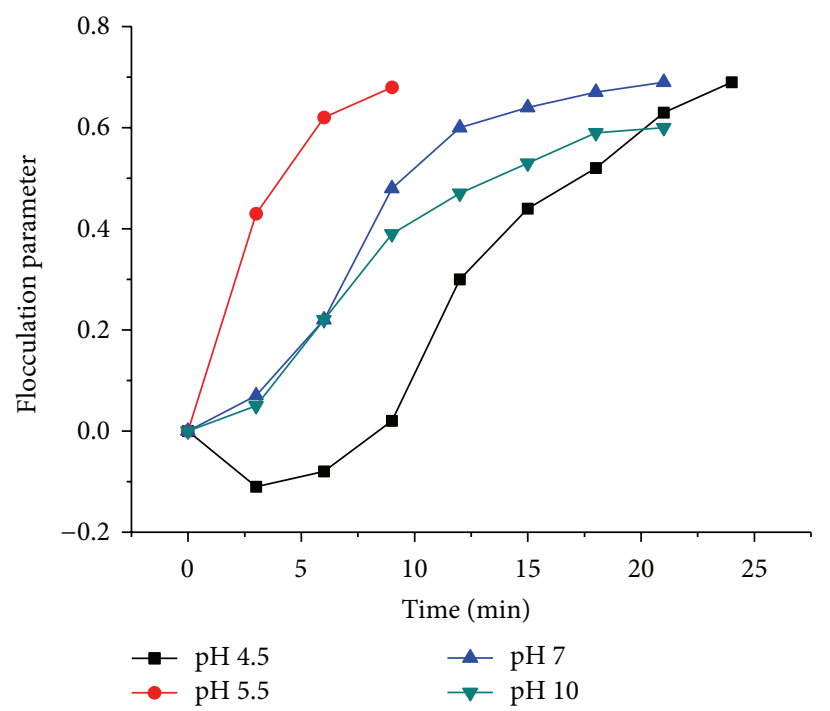

(a)

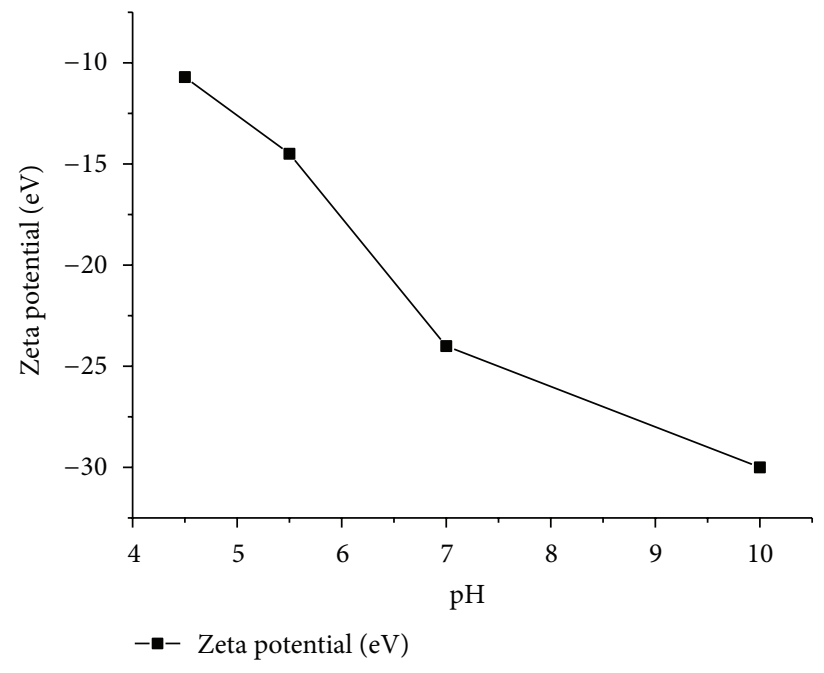

(b)

FIGURE 6: (a) Flocculation parameter of the SNPs with respect to time at different $\mathrm{pH}$ values and (b) zeta potential of SNPs synthesized using T. bispinosa peel extract.

after 15 min finally dropped to some extent. Decrease in the FP value indicates more stability of the nanoparticles [37, 38]. Consistent increase in the negative charge with respect to $\mathrm{pH}$ (from basic to acidic) indicates the rapid stabilisation of the nanoparticles (Figure 6(b)).

\section{Conclusions}

T. bispinosa can be used as a potential alternative to available chemical methods used for commercial production of SNPs due to its exceptionally high reducing potential which in turn is due to presence of high amount of antioxidants. It takes only $120 \mathrm{sec}$ at $28 \pm 2^{\circ} \mathrm{C}$ for the reduction of SNPs which makes it one of the most pivotal plant materials reported till date. SNPs formed at alkaline $\mathrm{pH}$ were highly stable and monodispersed proving their relevance for biological applications such as drug delivery. Cyclic voltammetry could be used as potential tool to assess the reduction potential of extracts with respect to time.

\section{Authors' Contribution}

Sunil Pandey and Ashmi Mewada have equal contributions to the work.

\section{Acknowledgments}

The authors wish to acknowledge the financial support provided by the authorities of SICES, Ambernath, and specially Mr. K. M. S. Nair and Mr. K. M. K. Nair. They give special thanks to Mrs. Chalke, TIFR Mumbai, for carrying SEM analysis. They acknowledge IIT Bombay, SAIF department, for carrying out ICP-AES analysis. The authors are obliged to reviewers for their valuable suggestions.

\section{References}

[1] D. R. Lovley, "Dissimilatory metal reduction," Annual Review of Microbiology, vol. 47, pp. 263-290, 1993.

[2] R. K. Das, B. B. Borthakur, and U. Bora, "Green synthesis of gold nanoparticles using ethanolic leaf extract of Centella asiatica," Materials Letters, vol. 64, no. 13, pp. 1445-1447, 2010.

[3] M. F. Lengke, M. E. Fleet, and G. Southam, "Morphology of gold nanoparticles synthesized by filamentous cyanobacteria from gold(I)-Thiosulfate and gold(III)-chloride complexes," Langmuir, vol. 22, no. 6, pp. 2780-2787, 2006.

[4] G. Singaravelu, J. S. Arockiamary, V. G. Kumar, and K. Govindaraju, "A novel extracellular synthesis of monodisperse gold nanoparticles using marine alga, Sargassum wightii Greville," Colloids and Surfaces B, vol. 57, no. 1, pp. 97-101, 2007.

[5] Y. Ishikawa, N. Shibata, and S. Fukatsu, "Highly oriented Si nanoparticles in $\mathrm{SiO}_{2}$ created by $\mathrm{Si}$ molecular beam epitaxy with oxygen implantation," Thin Solid Films, vol. 294, no. 1-2, pp. 227$230,1997$.

[6] J. R. Creighton, M. E. Coltrin, and J. J. Figiel, "Observations of gas-phase nanoparticles during InGaN metal-organic chemical vapor deposition," Applied Physics Letters, vol. 93, no. 17, Article ID 171906, 3 pages, 2008.

[7] A. Ahmad, S. Senapati, M. I. Khan, R. Kumar, and M. Sastry, "Extracellular biosynthesis of monodisperse gold nanoparticles by a novel extremophilic actinomycete, thermomonospora sp," Langmuir, vol. 19, no. 8, pp. 3550-3553, 2003.

[8] M. Kowshik, S. Ashtaputre, S. Kharrazi et al., "Extracellular synthesis of silver nanoparticles by a silver-tolerant yeast strain MKY3," Nanotechnology, vol. 14, no. 1, pp. 95-100, 2003.

[9] D. Mandal, M. E. Bolander, D. Mukhopadhyay, G. Sarkar, and P. Mukherjee, "The use of microorganisms for the formation of metal nanoparticles and their application," Applied Microbiology and Biotechnology, vol. 69, no. 5, pp. 485-492, 2006.

[10] T. C. McIntyre, S. C. McCutcheon, and J. L. Schnoor, Phytoremediation: Transformation and Control of Contaminants, John Wiley \& Sons, Hoboken, NJ, USA, 2003. 
[11] J. L. Gardea-Torresdey, E. Gomez, J. R. Peralta-Videa, J. G. Parsons, H. Troiani, and M. Jose-Yacaman, "Alfalfa sprouts: a natural source for the synthesis of silver nanoparticles," Langmuir, vol. 19, no. 4, pp. 1357-1361, 2003.

[12] S. S. Shankar, A. Rai, A. Ahmad, and M. Sastry, "Rapid synthesis of $\mathrm{Au}, \mathrm{Ag}$, and bimetallic Au core-Ag shell nanoparticles using Neem (Azadirachta indica) leaf broth," Journal of Colloid and Interface Science, vol. 275, no. 2, pp. 496-502, 2004.

[13] S. S. Shankar, A. Ahmad, and M. Sastry, "Geranium leaf assisted biosynthesis of silver nanoparticles," Biotechnology Progress, vol. 19, no. 6, pp. 1627-1631, 2003.

[14] S. P. Dubey, M. Lahtinen, and M. Sillanpää, "Green synthesis and characterizations of silver and gold nanoparticles using leaf extract of Rosa rugosa," Colloids and Surfaces A, vol. 364, no. 1-3, pp. 34-41, 2010.

[15] T. Santhoshkumar, A. A. Rahuman, G. Rajakumar et al., "Synthesis of silver nanoparticles using Nelumbo nucifera leaf extract and its larvicidal activity against malaria and filariasis vectors," Parasitology Research, vol. 108, no. 3, pp. 693-702, 2011.

[16] X. Yang, Q. Li, H. Wang et al., "Green synthesis of palladium nanoparticles using broth of Cinnamomum camphora leaf," Journal of Nanoparticle Research, vol. 12, no. 5, pp. 1589-1598, 2010.

[17] R. Charusheela, T. Chakrabarti, B. K. Sarangi, and R. A. Pandey, "Synthesis of silver nanoparticles from the aqueous extract of leaves of Ocimum sanctum for enhanced antibacterial activity," Journal of Chemistry, vol. 2013, Article ID 278925, 7 pages, 2013.

[18] J. Y. Song and B. S. Kim, "Rapid biological synthesis of silver nanoparticles using plant leaf extracts," Bioprocess and Biosystems Engineering, vol. 32, no. 1, pp. 79-84, 2009.

[19] Y. He, Z. Y. Du, H. B. Lv et al., "Green synthesis of silver nanoparticles by Chrysanthemum morifolium Ramat. extract and their application in clinical ultrasound gel," International Journal of Nanomedicine, vol. 8, pp. 1809-1815, 2013.

[20] C. S. Weisbecker, M. V. Merritt, and G. M. Whitesides, "Molecular self-assembly of aliphatic thiols on gold colloids," Langmuir, vol. 12, no. 16, pp. 3763-3772, 1996.

[21] M. Sastry, N. Lala, V. Patil, S. P. Chavan, and A. G. Chittiboyina, "Optical absorption study of the biotin-avidin interaction on colloidal silver and gold particles," Langmuir, vol. 14, no. 15, pp. 4138-4142, 1998.

[22] N. Ahmad, S. Sharma, V. N. Singh, S. F. Shamsi, A. Fatma, and B. R. Mehta, "Biosynthesis of silver nanoparticles from Desmodium triflorum: a novel approach towards weed utilization," Biotechnology Research International, vol. 2011, Article ID 454090, 8 pages, 2011.

[23] I. Maliszewska and M. Puzio, "Extracellular biosynthesis and antimicrobial activity of silver nanoparticles," Acta Physica Polonica A, vol. 116, pp. S160-S162, 2009.

[24] A. M. Fayaz, K. Balaji, M. Girilal, R. Yadav, P. T. Kalaichelvan, and R. Venketesan, "Biogenic synthesis of silver nanoparticles and their synergistic effect with antibiotics: a study against gram-positive and gram-negative bacteria," Nanomedicine, vol. 6, no. 1, pp. e103-e109, 2010.

[25] C. A. Mirkin, R. L. Letsinger, R. C. Mucic, and J. J. Storhoff, "A DNA-based method for rationally assembling nanoparticles into macroscopic materials," Nature, vol. 382, no. 6592, pp. 607609, 1996.

[26] D. K. Bhui, H. Bar, P. Sarkar, G. P. Sahoo, S. P. De, and A. Misra, "Synthesis and UV-vis spectroscopic study of silver nanoparticles in aqueous SDS solution," Journal of Molecular Liquids, vol. 145, no. 1, pp. 33-37, 2009.
[27] R. Pulido, L. Bravo, and F. Saura-Calixto, "Antioxidant activity of dietary polyphenols as determined by a modified ferric reducing/antioxidant power assay," Journal of Agricultural and Food Chemistry, vol. 48, no. 8, pp. 3396-3402, 2000.

[28] M.-H. Siess, A.-M. Le Bon, M.-C. Canivenc-Lavier et al., "Flavonoids of honey and propolis: characterisation and effect on hepatic drug metabolising enzymes and benzo(a) pyrene DNA binding in rats," Journal of Agricultural and Food Chemistry, vol. 44, no. 8, pp. 2297-2301, 1996.

[29] F. Shahidi and M. Naczk, "Methods of analysis and quantification of phenolic compounds," in Food Phenolics: Sources, Chemistry, Effects and Applications, pp. 147-179, Technomic, Lancaster, UK, 1995.

[30] F. Shahidi and M. Naczk, "Antioxidant properties of food phenolics," in Phenolics in Food and Nutraceuticals, pp. 403442, CRC Press, Boca Raton, Fla, USA, 2004.

[31] S. L. Smitha, D. Philip, and K. G. Gopchandran, "Green synthesis of gold nanoparticles using Cinnamomum zeylanicum leaf broth," Spectrochimica Acta A, vol. 74, no. 3, pp. 735-739, 2009.

[32] A. Mewada, S. Pandey, G. Oza et al., "A novel report on assessing $\mathrm{pH}$ dependent role of nitrate reductase on green biofabrication on gold nanoplates and nanocubes," Journal of Bionanoscience, vol. 7, no. 2, pp. 174-180, 2013.

[33] R. Lévy, N. T. K. Thanh, R. Christopher Doty et al., "Rational and combinatorial design of peptide capping ligands for gold nanoparticles," Journal of the American Chemical Society, vol. 126, no. 32, pp. 10076-10084, 2004.

[34] H. Ma, B. Yin, S. Wang et al., "Synthesis of silver and gold nanoparticles by a novel electrochemical method," ChemPhysChem, vol. 5, no. 1, pp. 68-75, 2004.

[35] C. G. Blatchford, J. R. Campbell, and J. A. Creighton, "Plasma resonance-enhanced raman scattering by absorbates on gold colloids: the effects of aggregation," Surface Science, vol. 120, no. 2, pp. 435-455, 1982.

[36] M. Quinten and U. Kreibig, "Optical properties of aggregates of small metal particles," Surface Science, vol. 172, no. 3, pp. 557$577,1986$.

[37] K. S. Mayya, V. Patil, and M. Sastry, "On the stability of carboxylic acid derivatized gold colloidal particles: the role of colloidal solution $\mathrm{pH}$ studied by optical absorption spectroscopy," Langmuir, vol. 13, no. 15, pp. 3944-3947, 1997.

[38] M. Thakur, S. Pandey, A. Mewada, R. Shah, G. Oza, and M. Sharon, "Understanding the stability of silver nanoparticles biofabricated using Acacia arabica (Babool gum) and its hostile effect on microorganisms," Spectrochimica Acta A, vol. 109, pp. 344-347, 2013. 



Submit your manuscripts at http://www.hindawi.com
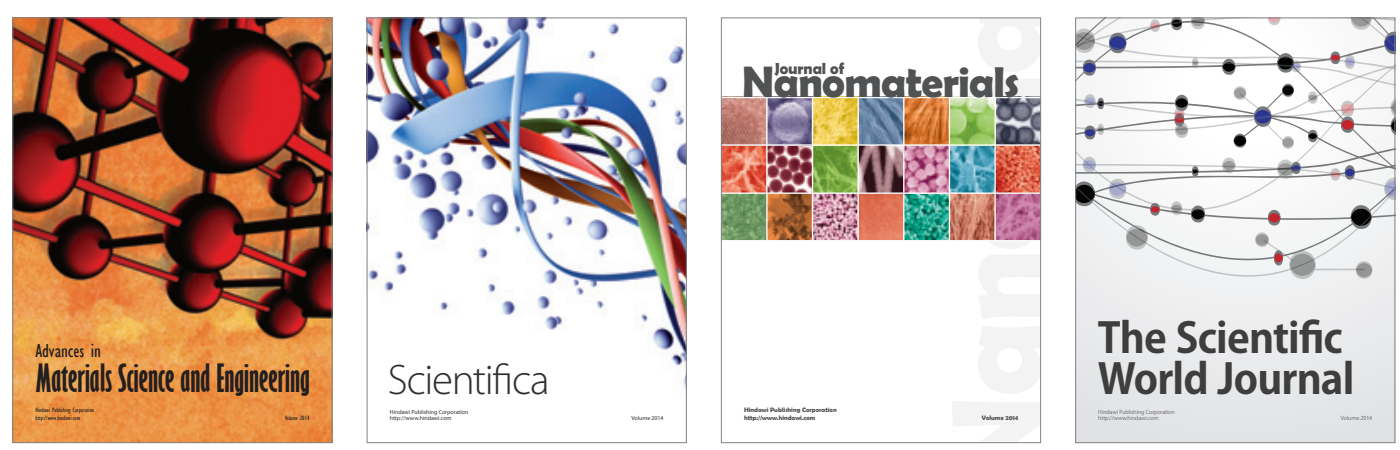

\section{The Scientific World Journal}
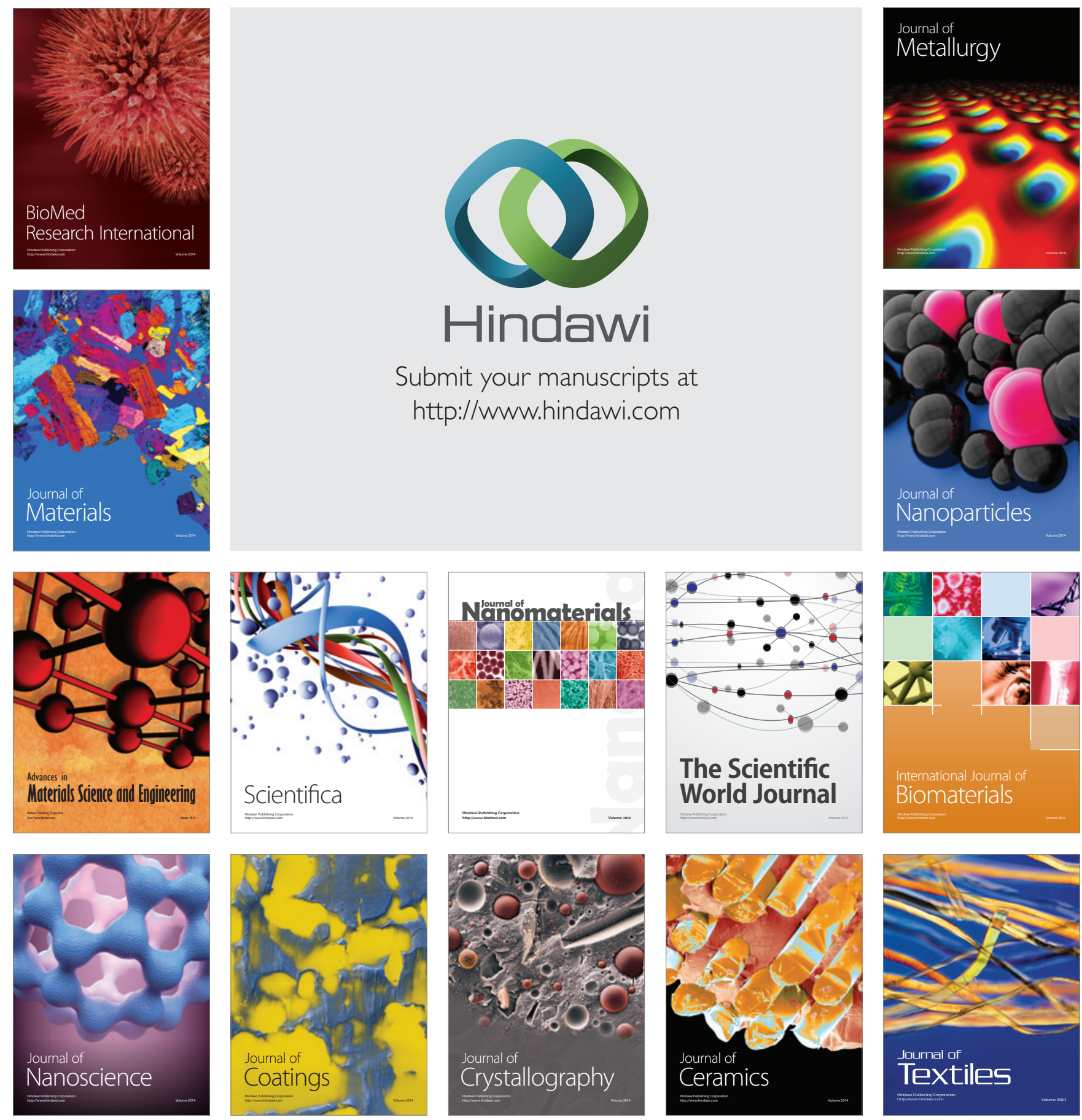